\title{
Gastric xanthelasma may be a warning sign of intestinal metaplasia: A cross-sectional study
}

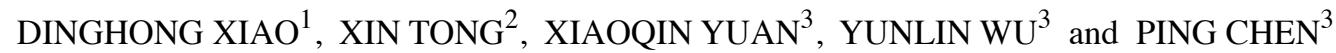 \\ Departments of ${ }^{1}$ Gastroenterology and ${ }^{2}$ Oncology, Jiading Hospital of Traditional Chinese Medicine, \\ Shanghai 201800; ${ }^{3}$ Department of Gastroenterology, Ruijin Hospital North, \\ Shanghai Jiaotong University School of Medicine, Shanghai 201801, P.R. China
}

Received February 19, 2020; Accepted May 26, 2020

DOI: $10.3892 /$ or.2020.7651

\begin{abstract}
Certain conflicting conclusions have been drawn that gastric xanthelasma is related to H.pylori, atrophic gastritis, intestinal metaplasia, and early gastric cancer. The aim of this study was to examine the relationship between gastric xanthelasma and upper gastrointestinal (GI) endoscopic or pathological features. A cross-sectional study was completed. A total of 8,634 patients who underwent stomach biopsy and who had no gastrectomy history were enrolled in the study. The patients were divided into two groups according to the presence or absence of gastric xanthelasma. The relationship between gastric xanthelasma and demographic characteristics (including age and sex), endoscopic features (including peptic ulcer, bile reflux, and gastric poly), or pathological features (including atrophy, intestinal metaplasia, H. pylori, dysplasia, and gastric cancer) was analyzed. Age/sex matched analysis was also performed to exclude the influence of age and sex. The results revealed that out of the 8,634 patients, $3.54 \%$ patients had xanthelasma. Gastric xanthelasma was significantly associated with age (55.76 vs. 49.17 years, $\mathrm{P}<0.0001$ ), duodenal ulcer (OR 0.860, 95\% CI 0.369-0.923), atrophy (OR 1.839, 95\% CI 1.432-2.362), and intestinal metaplasia (OR 3.296, 95\% CI 2.612-4.159). Binary logistic analysis revealed that age (OR 1.027, 95\% CI 1.017-1.037) and intestinal metaplasia (OR 2.700, 95\% CI 2.090-3.487) were independently related to gastric xanthelasma. Age/sex matched control binary logistic analysis revealed that gastric xanthelasma was significantly associated with presence of intestinal metaplasia (OR 2.338, 95\% CI 1.659-3.297). There was no difference in the number $(\mathrm{P}=0.427)$ and location $(\mathrm{P}>0.05)$ of gastric xanthelasma for intestinal metaplasia. In conclusion, gastric xanthelasma may be an independent endoscopic warning sign of intestinal metaplasia.
\end{abstract}

Correspondence to: Dr Ping Chen, Department of Gastroenterology, Ruijin Hospital North, Shanghai Jiaotong University School of Medicine, 999 Xiwang Road, Shanghai 201801, P.R. China

E-mail: chenping714@aliyun.com

Key words: gastric xanthelasma, intestinal metaplasia, atrophy

\section{Introduction}

Gastric xanthelasma is a benign lesion that was first described in 1887 (1). It is characterized by the presence of lipid islands in the gastric mucosa (2), and infiltration of lamina propria with foamy macrophages under the microscope (3). The prevalence of gastric xanthelasma ranges from 0.018 to $7.7 \%$ according to the reported literature (4-10). The etiology and pathogenesis are still unclear. Foamy macrophages broken-down to the cell membranes after mucosal damage to the stomach and abnormality of the lipid metabolism are the main hypotheses to explain the etiology and pathogenesis $(5,11)$.

Certain studies have evaluated the correlation between gastric xanthelasma and numerous factors, such as $H$. pylori, atrophic gastritis, intestinal metaplasia, and early gastric cancer, but there were some conflicting conclusions. Research by Hori and Sutsumi revealed that gastric xanthelasma was related to H. pylori (12); however, research by Yi revealed a negative result concerning $H$. pylori (5). Studies by both Chen et al and Köksal et al found that gastric xanthelasma was related to atrophic gastritis and intestinal metaplasia $(10,13)$. Nevertheless, research from Japan indicated that xanthelasma may be a warning sign for the presence of early gastric cancer $(4,14)$.

The follow-up strategy varies among patients who have different risks of gastric cancer. Distinctly understanding the risk factors of gastric xanthelasma is important to manage patients who have a high risk of developing gastric cancer. Therefore, we retrospectively analysed the relationship between gastric xanthelasma and upper gastrointestinal (GI) endoscopic or pathological features by performing a cross-sectional study.

\section{Patients and methods}

Study design. The present study is a cross-sectional retrospective study that was performed at the Department of Gastroenterology of Shanghai Ruijin Hospital North between July 2016 and June 2017. All of the patients signed an informed consent form before the procedure. The informed consent forms obtained the consent of patients to use their clinical data, and assured them that no identifiable personal information would be disclosed. The present study was approved by the 


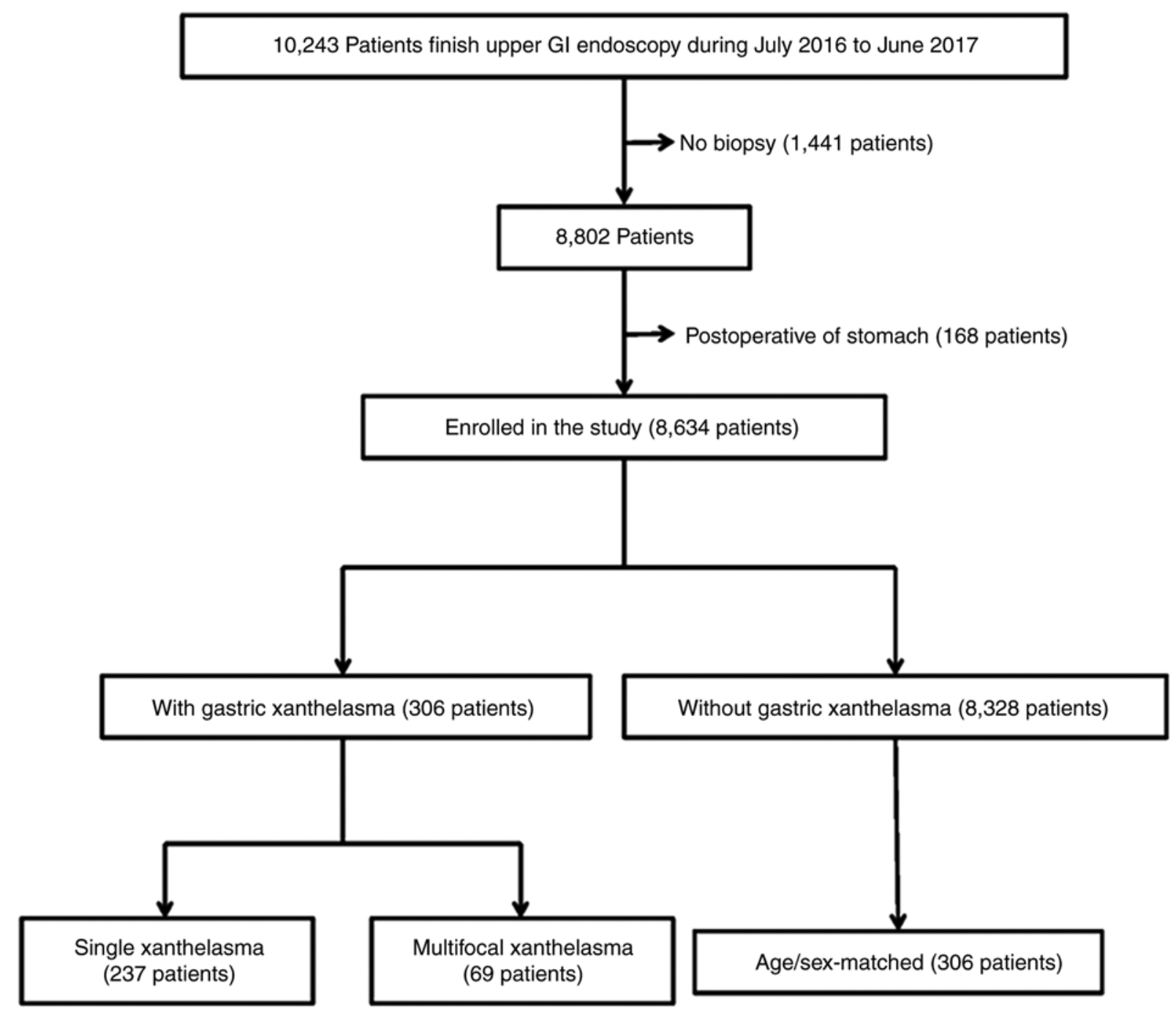

Figure 1. Flow chart of the study.

Institutional Review Board of Jiading Hospital of Traditional Chinese Medicine (Shanghai, China) (approval no. 2017005).

Patients. A total of 10,243 patients underwent upper GI endoscopic examinations. The patients who did not have a stomach biopsy pathological result and who had previously undergone gastrectomy were excluded from this study. The following factors were examined retrospectively: Age, sex, endoscopy findings, and pathological results. Finally, 8,634 patients were enrolled in the study, as presented in Fig. 1. To exclude the influence of age and sex, controls matched with the patients in terms of age and sex were also analyzed.

Endoscopic procedure. Upper GI endoscopic examination was performed using pan-endoscopes (model name: Fujinon VP-4450HD-EG-590WR; Fujifilm) equipped with the Picture Archiving and Communication System (PacsVideo diagnostic work station, Neusoft Group Co., Ltd.). All of the examinations were performed by 11 experienced endoscopists, who carefully observed the esophagus, the entire stomach, and the duodenum. The endoscopy findings, including peptic ulcer, bile reflux, gastric polyp, and gastric xanthelasma, were recorded. Two non-targeted biopsies in the antrum were routine biopsies. Additional biopsies were collected where lesions were found. The diagnosis of gastric xanthelasma was based on endoscopy and histopathologic examination of biopsy samples. Anatomic locations of all xanthelasmas were recorded during the procedure.

Histologic evaluation. The biopsy samples were fixed in $4 \%$ formalin, embedded in paraffin in room temperature, and were performed on $4-\mu \mathrm{m}$ sections. The histopathological changes of specimens were stained by hematoxylin-eosin staining and were observed under light microscope at $\mathrm{x} 400$ magnification (Olympus BX-51; Olympus). Histological diagnosis was independently performed by two experienced pathologists. The pathological results, including simple atrophy, intestinal metaplasia, $H$. pylori, dysplasia, and gastric cancer, were recorded according to the updated Sydney system (15).

Statistical analysis. SPSS 19.0 (IBM Corp.) statistical package for Windows was used for the statistical analysis. Data concerning age were expressed as the mean \pm SD. Differences in age between the two groups were analyzed by the independent samples t-test or the Mann-Whitney $U$ test if the data 
Table I. Basic characteristics of the study population with and without gastric xanthelasma.

\begin{tabular}{|c|c|c|c|c|c|}
\hline Characteristics & $\begin{array}{l}\text { With xanthelasma } \\
(\mathrm{n}=306) \mathrm{n}(\%)\end{array}$ & $\begin{array}{l}\text { Without xanthelasma } \\
\quad(\mathrm{n}=8,328) \mathrm{n}(\%)\end{array}$ & OR & $95 \% \mathrm{CI}$ & P-value \\
\hline Age (years) & $55.76 \pm 11.18$ & $49.17 \pm 13.58$ & & & $<0.0001^{\mathrm{a}}$ \\
\hline Sex & & & 0.860 & $0.684-1.081$ & $0.201^{\mathrm{b}}$ \\
\hline Male & $164(53.6 \%)$ & $4,150(49.8 \%)$ & & & \\
\hline Female & $142(46.4 \%)$ & $4,178(50.2 \%)$ & & & \\
\hline Gastric ulcer & & & 0.761 & $0.402-1.442$ & $0.470^{\mathrm{b}}$ \\
\hline Present & $10(3.3 \%)$ & $354(4.3 \%)$ & & & \\
\hline Absent & $296(96.7 \%)$ & $7,974(95.7 \%)$ & & & \\
\hline Duodenal ulcer & & & 0.584 & $0.369-0.923$ & $0.018^{\mathrm{b}}$ \\
\hline Present & $20(6.5 \%)$ & $891(10.7 \%)$ & & & \\
\hline Absent & $286(93.5 \%)$ & $7,437(89.3 \%)$ & & & \\
\hline Bile reflux & & & 0.857 & $0.561-1.309$ & $0.542^{\mathrm{b}}$ \\
\hline Present & $24(8.9 \%)$ & $752(9.3 \%)$ & & & \\
\hline Absent & $282(91.1 \%)$ & $7,576(90.7 \%)$ & & & \\
\hline Gastric polyp & & & 1.178 & $0.811-1.712$ & $0.363^{\mathrm{b}}$ \\
\hline Present & $32(10.5 \%)$ & $751(9.0 \%)$ & & & \\
\hline Absent & $274(89.5 \%)$ & $7,577(91.0 \%)$ & & & \\
\hline Atrophy & & & 1.839 & $1.432-2.362$ & $<0.0001^{\mathrm{b}}$ \\
\hline Present & $92(30.1 \%)$ & $1,578(18.9 \%)$ & & & \\
\hline Absent & $214(69.9 \%)$ & $6,750(81.1 \%)$ & & & \\
\hline Intestinal metaplasia & & & 3.296 & $2.612-4.159$ & $<0.0001^{\mathrm{b}}$ \\
\hline Present & $181(59.2 \%)$ & $2,542(30.5 \%)$ & & & \\
\hline Absent & $125(40.8 \%)$ & $5,786(69.5 \%)$ & & & \\
\hline H. pylori & & & 1.018 & $0.795-1.305$ & $0.899^{\mathrm{b}}$ \\
\hline Present & $93(30.4 \%)$ & $2,499(30.0 \%)$ & & & \\
\hline Absent & $213(69.6 \%)$ & $5,829(70.0 \%)$ & & & \\
\hline Dysplasia & & & 0.997 & $0.996-0.998$ & $0.9999^{\mathrm{b}}$ \\
\hline Present & $0(0)$ & $27(0.3 \%)$ & & & \\
\hline Absent & $306(100 \%)$ & $8,301(99.7 \%)$ & & & \\
\hline Gastric cancer & & & 1.112 & $0.407-3.043$ & $0.836^{\mathrm{b}}$ \\
\hline Present & $4(1.3 \%)$ & $98(1.2 \%)$ & & & \\
\hline Absent & $302(98.7 \%)$ & $8,230(98.8 \%)$ & & & \\
\hline
\end{tabular}

${ }^{\mathrm{a}}$ Mann-Whitney U Test; ${ }^{\mathrm{b}}$ Fisher's exact test.

were not parametric. The Chi-square test was used to compare categorical variables in different groups, and the Fisher's exact test was used when low anticipated cell counts were noted. Both univariate analysis and binary logistic regression were used to analyze the association of gastric xanthelasma with other factors. All of the calculated P-values were two-tailed. $\mathrm{P}<0.05$ was considered to indicate a statistically significant difference.

\section{Results}

Characteristics of patients with and without gastric xanthelasma. Upon examination of the 8,634 patients, a total of $306(3.54 \%)$ patients had xanthelasma. According to the presence of gastric xanthelasma, the patients were divided
Table II. Binary logistic analysis of factors related to gastric xanthelasma.

\begin{tabular}{lccc}
\hline Characteristics & OR & $95 \%$ CI & P-value \\
\hline Age & 1.027 & $1.017-1.037$ & $<0.0001$ \\
Duodenal ulcer & 0.650 & $0.410-1.032$ & 0.068 \\
Atrophy & 0.945 & $0.720-1.240$ & 0.683 \\
Intestinal metaplasia & 2.700 & $2.090-3.487$ & $<0.0001$ \\
\hline
\end{tabular}

into the following two groups: With xanthelasma and without xanthelasma. The clinical characteristics of the two groups are summarized in Table I. The average age of patients with 
Table III. Comparison between patients with gastric xanthelasma and age/sex-matched controls without gastric xanthelasma.

\begin{tabular}{|c|c|c|c|c|c|c|}
\hline Characteristics & $\begin{array}{l}\text { With xanthelasma } \\
(\mathrm{n}=306) \mathrm{n}(\%)\end{array}$ & $\begin{array}{l}\text { Without xanthelasma } \\
\quad(\mathrm{n}=306) \mathrm{n}(\%)\end{array}$ & OR & $95 \% \mathrm{CI}$ & $\chi^{2}$ & P-value \\
\hline Duodenal ulcer & & & 0.949 & $0.503-1.789$ & 0.026 & $0.872^{\mathrm{a}}$ \\
\hline Present & $20(6.5)$ & $21(6.9)$ & & & & \\
\hline Absent & $286(93.5)$ & $285(93.1)$ & & & & \\
\hline Atrophy & & & 1.763 & $1.214-2.560$ & 8.963 & $0.003^{\mathrm{a}}$ \\
\hline Present & $92(30.1)$ & $60(19.6)$ & & & & \\
\hline Absent & $214(69.9)$ & $246(80.4)$ & & & & \\
\hline Intestinal metaplasia & & & 2.508 & $1.811-3.474$ & 31.174 & $<0.0001^{\mathrm{a}}$ \\
\hline Present & $181(59.2)$ & $112(36.6)$ & & & & \\
\hline Absent & $125(40.8)$ & $194(63.4)$ & & & & \\
\hline
\end{tabular}

${ }^{\mathrm{a} C h i}$-square test.

xanthelasma was 55.76 years, which was higher than that of those without xanthelasma $(\mathrm{P}<0.0001)$. The frequency of duodenal ulcer in the group with xanthelasma was less than that in the group without xanthelasma (6.5 vs. $10.7 \%$, $\mathrm{P}=0.020$ ). The frequency of atrophy in patients with xanthelasma was significantly higher than those without xanthelasma (30.1 vs. $18.9 \%$, OR 1.839, 95\% CI 1.432-2.362, $\mathrm{P}<0.0001$ ). The frequency of intestinal metaplasia in patients with xanthelasma was also significantly higher than that in those without xanthelasma (59.2 vs. 30.5\%, OR 3.296, 95\% CI 2.612-4.159, $\mathrm{P}<0.0001)$. However, there were no significant differences in sex, gastric ulcer, bile reflux, gastric polyp, H. pylori, dysplasia, and gastric cancer between the two groups.

The significantly different factors were evaluated by binary logistic analysis. The results revealed that age and intestinal metaplasia remained significantly related to gastric xanthelasma $(\mathrm{P}<0.0001$; Table II).

Comparison between patients with gastric xanthelasma and age/sex-matched controls without gastric xanthelasma. To eliminate the statistical influence of age, 306 patients without xanthelasma were matched in terms of age and sex with patients with xanthelasma. The differences in duodenal ulcer, atrophy, and intestinal metaplasia between these subgroups were analyzed. The Chi-square test revealed that between the two groups, there was no difference in the presence of duodenal ulcer $(\mathrm{P}=0.872)$, but there were significant differences in the presence of atrophy (OR 1.763, 95\% CI 1.214-2.560, $\mathrm{P}=0.003$ ) and intestinal metaplasia (OR 2.508, 95\% CI 1.811-3.474, P<0.0001) (Table III). Furthermore, binary logistic analysis revealed that intestinal metaplasia was significantly related to gastric xanthelasma (OR 2.338, 95\% CI, 1.659-3.297, $\mathrm{P}<0.0001)$, while atrophy was not related to gastric xanthelasma $(\mathrm{P}=0.221$; Table IV).

Comparison of basic characteristics between patients with single and multifocal xanthelasma. A subgroup analysis compared the basic characteristics between patients with single and multifocal xanthelasma. The average ages of patients with single and multifocal xanthelasma were 55.20
Table IV. Binary logistic analysis of factors related to gastric xanthelasma.

\begin{tabular}{lccc}
\hline Characteristics & OR & $95 \%$ CI & P-value \\
\hline Atrophy & 1.284 & $0.861-1.916$ & 0.221 \\
Intestinal metaplasia & 2.338 & $1.659-3.297$ & $<0.0001$ \\
\hline
\end{tabular}

and 57.99 years, respectively, which revealed no significant difference $(\mathrm{P}=0.074)$. Other factors, including sex, atrophy, intestinal metaplasia, H. pylori, and gastric cancer also exhibited no differences $(\mathrm{P}>0.05$; Table $\mathrm{V})$.

Comparison of localization characteristics between gastric xanthelasma patients with and without intestinal metaplasia. The locations of gastric xanthelasma were recorded as cardia, fundus, corpus, angle, and antrum of the stomach. Subgroup analysis compared localization characteristics between gastric xanthelasma patients with and without intestinal metaplasia; however, there were no significant differences in localization characteristics $(\mathrm{P}>0.05$; Table VI).

\section{Discussion}

The prevalence of gastric xanthelasma was $3.54 \%$ in our study, which is consistent with that in the reported literature and is higher than a prevalence of $0.8 \%$ reported from China in 1989 and 2017 (10). The present study revealed that gastric xanthelasma was associated with age, duodenal ulcer, atrophy, and intestinal metaplasia using univariate analysis. Binary logistic analysis revealed that gastric xanthelasma was significantly associated with age and intestinal metaplasia. After adjusting for age, xanthelasma remained associated with intestinal metaplasia. Number and location of gastric xanthelasma exhibited no difference for intestinal metaplasia.

Previous research has indicated that gastric xanthelasma had a strong correlation with atrophy $(16,17)$, intestinal metaplasia and early gastric cancer $(18,19)$. Furthermore, in 
Table V. Basic characteristics of the study population with single and multifocal xanthelasma.

\begin{tabular}{|c|c|c|c|c|}
\hline Characteristics & $\begin{array}{l}\text { Single xanthelasma } \\
\qquad(\mathrm{n}=237) \mathrm{n}(\%)\end{array}$ & $\begin{array}{l}\text { Multifocal xanthelasma } \\
\qquad(\mathrm{n}=69) \mathrm{n}(\%)\end{array}$ & $\chi^{2}$ & P-value \\
\hline Age (years) & $55.20 \pm 11.62$ & $57.99 \pm 10.43$ & & $0.074^{\mathrm{a}}$ \\
\hline Sex & & & 1.216 & $0.270^{\mathrm{b}}$ \\
\hline Male & $123(51.9 \%)$ & $41(59.4 \%)$ & & \\
\hline Female & $114(48.1 \%)$ & $28(40.6 \%)$ & & \\
\hline Atrophy & & & 1.052 & $0.305^{\mathrm{b}}$ \\
\hline Present & $64(27.0 \%)$ & $23(33.3 \%)$ & & \\
\hline Absent & $173(73.0 \%)$ & $46(66.7 \%)$ & & \\
\hline Intestinal metaplasia & & & 0.630 & $0.427^{\mathrm{b}}$ \\
\hline Present & $135(57.0 \%)$ & $43(62.3 \%)$ & & \\
\hline Absent & $102(43.0 \%)$ & $26(37.7 \%)$ & & \\
\hline H.pylori & & & 1.472 & $0.225^{\mathrm{b}}$ \\
\hline Present & $71(30.0 \%)$ & $26(37.7 \%)$ & & \\
\hline Absent & $166(70.0 \%)$ & $43(62.3 \%)$ & & \\
\hline Gastric cancer & & & & $0.9999^{c}$ \\
\hline Present & $3(1.3 \%)$ & $1(1.4 \%)$ & & \\
\hline Absent & $234(98.7 \%)$ & $68(98.6 \%)$ & & \\
\hline
\end{tabular}

${ }^{\mathrm{a}}$ Mann-Whitney U Test; ${ }^{\mathrm{b}}$ Chi-square test; ' ${ }^{\mathrm{F}}$ isher's exact test.

Table VI. Location characteristics of gastric xanthelasma with or without intestinal metaplasia.

\begin{tabular}{|c|c|c|c|c|}
\hline Location & $\begin{array}{c}\text { With } \\
\text { intestinal } \\
\text { metaplasia } \\
(n=181)\end{array}$ & $\begin{array}{l}\text { Without } \\
\text { intestinal } \\
\text { metaplasia } \\
(n=125)\end{array}$ & $\chi^{2}$ & P-value \\
\hline Cardia & & & & $0.479^{a}$ \\
\hline Present & 6 & 2 & & \\
\hline Absent & 175 & 123 & & \\
\hline Fundus & & & 0.287 & $0.592^{\mathrm{b}}$ \\
\hline Present & 9 & 8 & & \\
\hline Absent & 172 & 117 & & \\
\hline Corpus & & & 0.153 & $0.696^{\mathrm{b}}$ \\
\hline Present & 26 & 16 & & \\
\hline Absent & 155 & 109 & & \\
\hline Angle & & & 1.320 & $0.251^{\mathrm{b}}$ \\
\hline Present & 11 & 12 & & \\
\hline Absent & 170 & 113 & & \\
\hline Antrum & & & 3.425 & $0.064^{\mathrm{b}}$ \\
\hline Present & 79 & 68 & & \\
\hline Absent & 102 & 57 & & \\
\hline
\end{tabular}

${ }^{\mathrm{a}}$ Fisher's exact test; ${ }^{\mathrm{b}} \mathrm{Chi}$-square test.

a previous study, 44.4-76.0\% of gastric xanthelasma patients were diagnosed as having atrophy (14). Isomoto et al found that gastric xanthelasma patients had more severe atrophy than controls (17). The present study revealed that $30.1 \%$ of gastric xanthelasma patients had atrophy, and this rate was lower than that reported in the literature. Moreover, in previous studies, 13.3-48.9\% of gastric xanthelasma patients were diagnosed as having intestinal metaplasia $(18,19)$. However, the present data revealed that $59.2 \%$ of gastric xanthelasma patients had intestinal metaplasia, which is the highest ever reported. Furthermore, in previous research, 14.0-20.1\% of gastric xanthelasma patients were diagnosed as having early gastric cancer, and 47.6-72.5\% of early gastric cancer patients were observed to have gastric xanthelasma (16). However, the present research indicated that gastric xanthelasma patients showed no significant increase in early gastric cancer when compared to those without gastric xanthelasma, which is consistent with the result reported by Köksal et al (13).

Notably, binary logistic analysis revealed that gastric xanthelasma was an independent risk factor for intestinal metaplasia, not for atrophy and early gastric cancer, which is inconsistent with the literature (16). Sekikawa et al conducted research on the association beween gastric xanthelasma and other endoscopic examinations results, including atrophy, gastric ulcer, duodenal ulcer, reflux esophagitis, fundic gland polyp, and gastric cancer, but they did not analyze the association between gastric xanthelasma and pathological results of gastric mucosa (14). Two researchers completed the analysis of the relationship between gastric xanthelasma and pathological results of gastric mucosa; however, multivariate correlation analysis was not performed, and the authors concluded that gastric xanthelasma is a warning marker of multifocal atrophic gastritis and advanced intestinal metaplasia (13). The present univariate analysis revealed that gastric xanthelasma 
was significantly associated to both atrophy and intestinal metaplasia, while binary logistic analysis revealed that atrophy was not associated to gastric xanthelasma. This indicated that atrophy was not an independent factor for gastric xanthelasma.

Researchers from Japan revealed that gastric xanthelasma was an independent risk factor for early gastric cancer (16). However, the present study did not derive the same conclusion. There are some possible reasons for this discrepancy. First, the detection rate of early gastric cancer was $61.7 \%$ in 2008 , according to the nationwide population-based data in Japan (20); however, this rate is lower than $10 \%$ in China (21). Second, image enhanced endoscopy (IEE), such as magnifying endoscopy with narrow-band imaging, is generally used in Japan; however, IEE is not prevalently used in China (22).

Moreover, $30 \%$ of patients were diagnosed as having $H$. pylori infection by pathologists in our study, but there was no difference between patients with and without gastric xanthelasma. A study from South Korea presented the same conclusion concerning $H$. pylori (5), however two researchers in the 1990s found that gastric xanthelasma was closely associated with $H$. pylori $(12,17)$.

In the present study it was also revealed the number and location of gastric xanthelasma exhibited no difference for intestinal metaplasia. However, research by Köksal et al revealed that multiple xanthelasma patients had a higher probability of being diagnosed as having intestinal metaplasia than those with single xanthelasmas, and the location of gastric xanthelasma exhibited no difference (13).

While the present research is single-center and retrospective, the data are integral and credible. The present study, however has some limitations. First, a single-center study may lack representation; therefore, multicenter research is required. Second, in the present research, $H$. pylori infection was based on pathology diagnosis and we did not have complete data of other tests, which may have caused bias while analyzing the relationship between gastric xanthelasma and $H$. pylori infection. Third, due to only two non-targeted biopsies in our routine biopsy, the OLGA and OLGIM systems could not be used to evaluate the correlation between gastric xanthelasma and the grade of atrophy and intestinal metaplasia.

In summary, gastric xanthelasma was associated with age and intestinal metaplasia. Age- and sex-matched analysis revealed that gastric xanthelasma was significantly associated with intestinal metaplasia. This indicates that gastric xanthelasma may be an independent endoscopic warning sign of intestinal metaplasia. Therefore, when gastric xanthelasma is encountered during an endoscopic procedure, more attention should be paid since it may indicate intestinal metaplasia of the gastric mucosa.

\section{Acknowledgements}

We would like to thank Professor Meiyu Shi from Shanghai University of Traditional Chinese Medicine for biostatistics support.

\section{Funding}

The present study was supported by the Chinese Medicine Key Disciplines of Jiading District (grant no. 2017-ZYZDZK-01) and the Shanghai Health and Wellness Commission Fund (grant no. 201640231).

\section{Availability of data and materials}

The datasets used during the present study are available from the corresponding author upon reasonable request.

\section{Authors' contributions}

DX and PC conceived and designed the study. XY, YW and PC provided administrative support and study patients. DX collected and assembled the data. DX and XT performed data analysis and interpretation. All of the authors contributed to the writing and final approval of the manuscript and agree to be accountable for all aspects of the research in ensuring that the accuracy or integrity of any part of the work are appropriately investigated and resolved.

\section{Ethics approval and consent to participate}

All of the patients signed an informed consent form before the procedure. The informed consent forms obtained the consent of patients to use their clinical data, and assured them that no identifiable personal information would be disclosed. The present study was approved by the Institutional Review Board of Jiading Hospital of Traditional Chinese Medicine (Shanghai, China) (approval no. 2017005).

\section{Patient consent for publication}

Not applicable.

\section{Competing interests}

The authors declare that they have no competing interests.

\section{References}

1. Khachaturian T, Dinning JP and Earnest DL: Gastric xanthelasma in a patient after partial gastrectomy. Am J Gastroenterol 93: 1588-1589, 1998.

2. Kimura K, Hiramoto T and Buncher CR: Gastric xanthelasma. Arch Pathol 87: 110-117, 1969.

3. Coates AG, Nostrant TT, Wilson JA, Dobbins WO III and Agha FP: Gastric xanthomatosis and cholestasis. A causal relationship. Dig Dis Sci 31: 925-928, 1986.

4. Sekikawa A, Fukui H, Maruo T, Tsumura T, Kanesaka T, Okabe Y and Osaki Y: Gastric xanthelasma may be a warning sign for the presence of early gastric cancer. J Gastroenterol Hepatol 29: 951-956, 2014.

5. Yi SY: Dyslipidemia and $H$ pylori in gastric xanthomatosis. World J Gastroenterol 13: 4598-4601, 2007.

6. Gencosmanoglu R, Sen-Oran E, Kurtkaya-Yapicier O and Tozun N: Xanthelasmas of the upper gastrointestinal tract. J Gastroentero 39: 215-219, 2004.

7. Petrov S, Churtchev J, Mitova R, Boyanova L and Tarassov M: Xanthoma of the stomach-some morphometrical peculiarities and scanning electron microscopy. Hepatogastroenterology 46: 1220-1222, 1999

8. Chen YS, Lin JB, Dai KS, Deng BX, Xu LZ, Lin CD and Jiang ZG: Gastric xanthelasma. Chin Med J (Engl) 102: 639-643, 1989.

9. Terruzzi V, Minoli G, Butti GC and Rossini A: Gastric lipid islands in the gastric stump and in non-operated stomach. Endoscopy 12: 58-62, 1980. 
10. Chen Y, He XJ, Zhou MJ and Li YM: Gastric xanthelasma and metabolic disorders: A large retrospective study among Chinese population. World J Gastroenterol 23: 7756-7764, 2017.

11. Lechago J: Lipid islands of the stomach: An insular issue? Gastroenterology 110: 630-632, 1996.

12. Hori S and Tsutsumi Y: Helicobacter pylori infection in gastric xanthomas: Immunohistochemical analysis of 145 lesions. Pathol Int 46: 589-593, 1996.

13. Köksal AŞ, Suna N, Kalkan İH, Eminler AT, Sakaoğulları ŞZ, Turhan N, Saygılı F, Kuzu UB, Öztaş E and Parlak E: Is gastric xanthelasma an alarming endoscopic marker for advanced atrophic gastritis and intestinal metaplasia? Dig Dis Sci 61: 2949-2955, 2016.

14. Sekikawa A, Fukui H, Sada R, Fukuhara M, Marui S, Tanke G, Endo M, Ohara Y, Matsuda F, Nakajima J, et al: Gastric atrophy and xanthelasma are markers for predicting the development of early gastric cancer. J Gastroenterol 51: 35-42, 2016.

15. Dixon MF, Genta RM, Yardley JH and Correa P: Classification and grading of gastritis. The updated Sydney System. International Workshop on the Histopathology of Gastritis, Houston 1994. Am J Surg Pathol 20: 1161-1181, 1996.

16. Kitamura S, Muguruma N, Okamoto K, Tanahashi T, Fukuya A, Tanaka K, Fujimoto D, Kimura T, Miyamoto H, Bando Y, et al: Clinicopathological assessment of gastric xanthoma as potential predictive marker of gastric cancer. Digestion 96: 199-206, 2017
17. Isomoto $\mathrm{H}$, Mizuta $\mathrm{Y}$, Inoue $\mathrm{K}$, Matsuo $\mathrm{T}$, Hayakawa $\mathrm{T}$, Miyazaki M, Onita K, Takeshima F, Murase K, Shimokawa I and Kohno S: A close relationship between Helicobacter pylori infection and gastric xanthoma. Scand J Gastroenterol 34: 346-352, 1999.

18. Arévalo F and Cerrillo G: Gastric xantoma: Histological findings and clinico endoscopic characteristics in the 'Hospital Nacional 2 de Mayo' (1999-2005). Rev Gastroenterol Peru 25: 268-271, 2005 (In Spanish).

19. Moretó M, Ojembarrena E, Zaballa M, Tánago JG, Ibáñez S and Setién F: Retrospective endoscopic analysis of gastric xanthelasma in the non-operated stomach. Endoscopy 17:210-211, 1985.

20. The Editorial Board of the Cancer Statistics in Japan: Cancer Statistics in Japan 2016. In: Foundation for promotion of cancer research, Tokyo, pp92, 2017.

21. Du YQ, Cai QC, Liao Z, Fang J and Zhu CP: China experts consensus on the protocol of early gastric cancer screening (2017, Shanghai). Chin J Digest 38: 87-92, 2018

22. Yao K, Uedo N, Muto M and Ishikawa H: Development of an e-learning system for teaching endoscopists how to diagnose early gastric cancer: Basic principles for improving early detection. Gastric cancer 20 (Suppl 1): S28-S38, 2017. 